Review

\title{
Gene Expression Profiling as a Tool to Investigate the Molecular Machinery Activated during Hippocampal Neurodegeneration Induced by Trimethyltin (TMT) Administration
}

\author{
Wanda Lattanzi, Valentina Corvino, Valentina Di Maria, Fabrizio Michetti ${ }^{\dagger} * *$ \\ and Maria Concetta Geloso ${ }^{\dagger, *}$
}

Institute of Anatomy and Cell Biology, Università Cattolica del Sacro Cuore, Largo F. Vito 1, Rome 00168, Italy; E-Mails: wanda.lattanzi@rm.unicatt.it (W.L.);

valentina.corvino@rm.unicatt.it (V.C.); valentinadimaria1@virgilio.it (V.D.M.)

$\dagger$ These authors share senior authorship.

* Authors to whom correspondence should be addressed;

E-Mails: fabrizio.michetti@rm.unicatt.it (F.M.); mc.geloso@rm.unicatt.it (M.C.G.);

Tel.: +39-6-3015-5848 (F.M.); +39-6-3015-4915 (M.C.G.);

Fax: +39-6-3015-4813 (F.M. \& M.C.G.).

Received: 23 July 2013; in revised form: 6 August 2013 / Accepted: 8 August 2013 /

Published: 15 August 2013

\begin{abstract}
Trimethyltin (TMT) is an organotin compound exhibiting neurotoxicant effects selectively localized in the limbic system and especially marked in the hippocampus, in both experimental animal models and accidentally exposed humans. TMT administration causes selective neuronal death involving either the granular neurons of the dentate gyrus or the pyramidal cells of the Cornu Ammonis, with a different pattern of localization depending on the different species studied or the dosage schedule. TMT is broadly used to realize experimental models of hippocampal neurodegeneration associated with cognitive impairment and temporal lobe epilepsy, though the molecular mechanisms underlying the associated selective neuronal death are still not conclusively clarified. Experimental evidence indicates that TMT-induced neurodegeneration is a complex event involving different pathogenetic mechanisms, probably acting differently in animal and cell models, which include neuroinflammation, intracellular calcium overload, and oxidative stress. Microarray-based, genome-wide expression analysis has been used to investigate the molecular scenario occurring in the TMT-injured brain in different in vivo and in vitro models, producing an overwhelming amount of data. The aim of this review is
\end{abstract}


to discuss and rationalize the state-of-the-art on TMT-associated genome wide expression profiles in order to identify comparable and reproducible data that may allow focusing on significantly involved pathways.

Keywords: trimethyltin; neurodegeneration; gene expression profiling; hippocampus; animal models; cell culture

\section{Introduction}

The trisubstituted organotin compound trimethyltin chloride (TMT) is a potent neurotoxicant that causes, in mammalian brain, selective neuronal death specifically localized in the limbic system and, in particular, in the hippocampus [1,2]. Being widely used in both industry and agriculture as a constituent in fungicides and in plastic production [3], some cases of occupational or accidental human exposure to TMT have been described [2,4-6]. Exposed individuals exhibit neuropathologic and behavioural features similar to those that are elicited in experimental animal models of TMT intoxication, which thus offer a promising model of neurodegeneration, also susceptible to translational exploitations.

In rodents, TMT-administration induces behavioural alterations (hyperactivity and aggression), cognitive deficits (memory loss and learning impairment) and seizures [7,8], as a consequence of selective loss of specific hippocampal neuronal subpopulations, accompanied by reactive astrogliosis, microglial activation and enhanced neurogenesis. Consequently, it offers a valuable tool to study neuro-glial interactions associated with neuronal death processes and cellular and molecular events related to injury-induced neurogenesis [9-12]. Interestingly, TMT-induced hippocampal injury is not accompanied by blood-brain barrier (BBB) disruption [13-15], thus offering an instrument to study pathogenic events occurring before BBB impairment, including early resident microglial responses to neuronal damage [16].

The molecular mechanisms by which TMT induces selective neuronal death are still not conclusively clarified: different pathogenetic pathways, probably acting differently in in vivo and in vitro models, seem to be involved, including neuroinflammation, intracellular calcium overload, and oxidative stress $[7,17,18]$.

At the cellular level, mitochondrial dysfunction has been proposed as a possible causative factor of cell death $[19,20]$, through the involvement of a mitochondrial membrane bound protein termed stannin selectively expressed by TMT-sensitive cells [21].

Overall, the complete molecular scenario involved in TMT-induced neurodegeneration is still far from being clearly identified, though interesting insights have been obtained through genome-wide technologies, such as microarray analysis, aimed at global comparative gene expression profiling. Microarray analysis is a powerful investigative tool in molecular biology, as it allows the simultaneous expression profiling of the entire genome and has thus become a key technology in toxicology research [22]. To date, microarray technology has been employed to unravel the molecular mechanisms acting during TMT intoxication in distinct studies performed in the different models of TMT-induced neuronal death: the in vivo mouse and rat models and an in vitro cell culture 
model [10,15,23-27]. The aim of this review is to discuss and rationalize the state-of-the-art on gene expression profiling data regarding the TMT intoxication model, in order to identify comparable features that may allow focusing on significantly involved pathways.

\section{Different Models Used to Investigate TMT-Induced Gene Expression Profiling}

The neuropathological features of TMT-induced hippocampal damage differ among rodent species, depending on various parameters such as strain, age, dose, route of administration, essentially as a consequence of differences in metabolism and kinetics of the toxicant [1,28-30].

Therefore TMT-treatment offers at least two in vivo animal models for the study of different aspects of injury induced-neuronal death: a model of acute dentate granule cell apoptosis in mice, occurring within $48 \mathrm{~h}$ from TMT-administration, and a model of progressive CA1/CA3 pyramidal cell death in rats, developing over three weeks. The mouse model of TMT-induced selective granular cell apoptosis is mainly used to investigate early molecular events involved in neuronal death. Conversely, in the rat model, the intoxication is characterised by a subacute course; thus it is widely considered a model of chronic neurodegeneration $[18,31,32]$ and, according to some authors, it had been even regarded as a model resembling some features of Alzheimer's disease [33-36]. Since cell cultures have been usefully used to delineate selective features of TMT-induced neuronal death and to depict the specific role of glial cells in TMT-induced intoxication [37-46], gene expression profiling data have also been obtained in a homogeneous cellular model [27].

\subsection{The Mouse Model}

TMT-induced lesions in mice selectively affect dentate gyrus (DG) granule cells [1], with a different level of vulnerability depending on strain $[7,47,48]$. The involvement of the olfactory bulb and of the anterior olfactory nucleus has also been reported [49]. Neuronal death is induced by apoptosis, as demonstrated by chromatin condensation, DNA fragmentation and activated caspase-3 in degenerating granular cells [50,51].

Gene expression profiling data from murine hippocampus following TMT intoxication indicate the activation of molecular pathways involved in calcium homeostasis, inflammation, neurodegeneration, neurogenesis and apoptosis. In particular, relevant hints towards the clarification of the molecular scenario involved in TMT-induced selective brain damage could be gained from the original study by Lefebvre d'Hellencourt and Harry in the comparative expression profiling between the DG granular cells, selectively affected by the toxicant, and the essentially unaffected Cornus Ammonis (CA) pyramidal neurons, microdissected from the murine hippocampus (see Table 1). These authors observed, as early as $6 \mathrm{~h}$ post-TMT treatment in the DG of young mice (P21), a significantly increased expression of genes involved in neuronal differentiation and astrocyte activity (e.g., PEA-15 and NeuroD1), in inflammatory response ( $T$-cell antigen receptor and CD3 antigen zeta, among others), in cell adhesion (cadherin 5, CD14) and in apoptosis (DNA-damage inducible transcript 3, DDIT3) [24]. Conversely, they found only a slight expression modulation of the same genes in the CA at the same time point. At $18 \mathrm{~h}$ post-treatment, a significant overexpression of genes involved in neuronal survival (ATF3 and ATF4), cell cycle activation (cyclin D2, CDK5 and CDK7), migration (MIP1 alpha and beta, for instance) and differentiation (such as HSP70-5, inhibin beta-A and hairless) occurred in the DG [24]. 
At $18 \mathrm{~h}$, some of these transcripts (namely ATF3, ATF4 and DDIT3) displayed an even higher up-regulation in the CA region. The authors interpreted these data as specifically indicative of a cell survival response due to the presence of spared neurons in the DG (around $50 \%-60 \%$ ) and in the whole CA region [24].

Table 1. Overview of microarray-based genome-wide expression analysis in the in vivo trimethyltin (TMT)-induced models of neurodegeneration.

\begin{tabular}{|c|c|c|c|c|c|c|}
\hline $\begin{array}{l}\text { Model animal } \\
\text { (No. of } \\
\text { samples per } \\
\text { experimental } \\
\text { group) } \\
\end{array}$ & $\begin{array}{c}\text { Age at } \\
\text { treatment }\end{array}$ & $\begin{array}{c}\text { Rodent strain } \\
\text { - Animal } \\
\text { gender }^{\mathrm{a}}\end{array}$ & $\begin{array}{c}\text { TMT dosage } \\
\text { (administration } \\
\text { route) }\end{array}$ & $\begin{array}{c}\text { Hippocampal } \\
\text { tissue } \\
\text { specimen }\end{array}$ & $\begin{array}{c}\text { Tested } \\
\text { time points } \\
\text { (post-TMT } \\
\text { treatment) }\end{array}$ & Reference \\
\hline Mouse $(n=3)$ & Adult & $\begin{array}{c}\text { B6, } 129 \\
\text { Nfkb1 tmlBal } \\
\text { B6,129 2/J } \\
- \text { F/M } \\
\end{array}$ & $\begin{array}{c}\text { p-50 null: } \\
2.0 \mathrm{mg} / \mathrm{kg} \text {; } \\
\text { Non transgenic: } \\
2.25 \mathrm{mg} / \mathrm{kg}\end{array}$ & $\begin{array}{c}\text { Whole } \\
\text { hippocampus }\end{array}$ & 7 days & {$[23]$} \\
\hline Mouse $(n=10)$ & $\mathrm{P} 21$ & $\mathrm{CD}-1-\mathrm{M}$ & 3 mg/Kg (i.p.) & $\begin{array}{c}\text { Microdissected } \\
\text { DG and CA }\end{array}$ & $6-18 \mathrm{~h}$ & {$[24]$} \\
\hline Mouse $(n=3)$ & P120 & $\mathrm{CD}-1-\mathrm{M}$ & $2.4 \mathrm{mg} / \mathrm{Kg}$ (i.p.) & $\begin{array}{c}\text { Whole } \\
\text { hippocampus }\end{array}$ & $24 \mathrm{~h}$ & {$[15]$} \\
\hline Mouse $(n=3)$ & $\begin{array}{c}\mathrm{P} 21 \\
1 \text { year }\end{array}$ & $\mathrm{CD}-1-\mathrm{M}$ & $2.3 \mathrm{mg} / \mathrm{Kg}$ (i.p.) & $\begin{array}{c}\text { Microdissected } \\
\text { SGZ } \\
\end{array}$ & $48 \mathrm{~h}$ & {$[10]$} \\
\hline Rat $(n=3)$ & 6 weeks & $\begin{array}{c}\text { Sprague-- } \\
\text { Dawley - M }\end{array}$ & 9 mg/Kg (oral) & $\begin{array}{c}\text { Whole } \\
\text { hippocampus }\end{array}$ & $2-5$ days & {$[25]$} \\
\hline Rat $(n=3)$ & 6 weeks & $\begin{array}{c}\text { Long -Evans } \\
-\mathrm{F} / \mathrm{M}\end{array}$ & $8.0 \mathrm{mg} / \mathrm{Kg}$ (i.p.) & $\begin{array}{c}\text { Whole } \\
\text { hippocampus }\end{array}$ & $3-5$ days & {$[26]$} \\
\hline
\end{tabular}

${ }^{\mathrm{a}} \mathrm{F}$ : female; M: male; F/M: both sexes.

These findings would suggest that the acute response occurring in the target region of TMT intoxication (the DG) is represented by an early inflammatory response, followed by a stress-induced attempt of rescue, sustained by cell cycle activation, neuronal differentiation and glial activation. Overall, these observations allow hypothesizing that TMT-induced brain injury in the young murine model evokes a neurogenic stimulus.

Notably, most gene expression changes in this experimental condition were negative (i.e., expression inhibition). Downregulated genes included transcription factors, structural proteins, calcium regulators and signaling molecules, which did not display a significant differential expression across the two regions, indicating some kind of generalized molecular response across the whole hippocampus [24]. Interestingly, a higher extent of downregulation of genes involved in calcium homeostasis (including calbindin-28k, calmodulin and calcineurin) was observed in the DG. This functional group of genes actually displayed higher basal expression in the DG compared to the CA region, representing a possible hallmark in the DG molecular profile.

The hippocampal molecular profile of TMT intoxication has been also assessed at later time points in other studies (see Table 1). 
Funk and colleagues used the TMT-treated mouse to assess the neuroprotective role exerted by physical exercise on a brain injury model [15] (see Table 1). In this study, the gene expression profiling of the whole hippocampus $24 \mathrm{~h}$ post-TMT treatment allowed evidencing a prominent role of caspase-dependent apoptosis, in line with previous morphological evidence [50,51]. In particular, a significantly increased expression was observed for both caspase 3 and caspase 8, along with the nuclear factor of kappa light polypeptide gene enhancer in B-cells 1 (NFkB la), which blocks the nuclear translocation and phosphorylation of NFkB [52]. NFkB is known to be involved in the TMT-induced neurodegenerative events, participating in both neuronal survival related processes [23,53] and in neuronal damage [18,54,55]. In this case, it could be activated as a downstream messenger of the tumor necrosis factor alpha (TNFalpha)-dependent cascade driving the apoptotic process [56]. A slight but significant upregulation was also observed for the tumor necrosis factor receptor superfamily member 25 (Tnfrsf25), an agonist for the TNF receptor [15], thus confirming previous experimental data from in vivo and in vitro studies [37,44,45,57], and further supporting the specific role for TNF receptor signaling in TMT-mediated neuroinflammatory processes [45]. Interestingly, both $N F k B 1$ and TNFalpha are strongly upregulated in the hippocampus of patients affected by temporal lobe epilepsy associated with hippocampal sclerosis, supporting the role of neuroinflammation in human epilepsy [58] and the translational value of the molecular mechanisms activated by TMT in rodent hippocampus. Notably, the expression modulation induced by the TMT treatment in genes involved in cell death pathways was attenuated in mice with prior exercise, consistent with the postulated neuroprotective role [15]. As a whole, most differentially expressed genes that resulted during this study were annotated in inflammation and cell death functional categories. In particular, the interleukin-6 (IL-6)-related pathway was strongly activated by TMT, even in animals that performed exercise. The authors also found the upregulation of genes involved in cell survival and apoptosis inhibition (Hrasl, Fos oncogene, the signal transducer and activator of transcription-3 (Stat3) gene) [59]. Altogether, these data should point towards a cell survival strategy driven by pro-inflammatory signals, put in place within the murine hippocampus $24 \mathrm{~h}$ after TMT treatment $[60,61]$. These events could depict the molecular profile of glial activation occurring within the acute effects of TMT intoxication in the mouse model [8].

The same authors recently examined the modulation of gene expression profile of mice subgranular zone (SGZ) during TMT intoxication (see Table 1). They focused their attention, in particular, on the differential expression of $I L-1$ alpha and $I L-6$ genes, as a function of age during TMT intoxication. The transcript expression pattern confirmed that the IL-6-mediated pro-inflammatory signaling is involved in the TMT neurotoxicant effects displayed in the SGZ of adult (one year old) mice [10]. Conversely, they demonstrated that an interleukin 1 (IL-1)-related immune activation occurs in the SGZ of adolescent mice (P21), $48 \mathrm{~h}$ after TMT administration. The two alternative pathways may indeed reflect the age-related differences in proliferative response of neural progenitors upon the neurotoxicant administration. The original molecular scenario delineated in this study proposes an IL-1alpha-related signaling, involving $N F k B \quad 1$ among other genes overexpressed in adolescent compared to adult mice, as a putative alternative neurogenesis pathway [10].

In this respect, the study performed by Kassed and colleagues [23] (see Table 1), focusing on the pro-survival role of NFkB during the late phases of TMT-induced neurodegeneration, appears to be noteworthy. Gene expression profiling was studied by comparing TMT-treated wild type (wt) and 
genetically manipulated mice lacking the p50 subunit of NFkB protein complex (p50-null mice) with saline-injected controls at post-treatment day 7.

Genes related to immune function (e.g., Complement C1qB, chemokine CXC ligand 13), potential neuroprotective genes as heat shock proteins (e.g., Hsp70 and HRP12), lysosomal enzymes (e.g., beta-glicuronidase, cathepsin $C$ and D), genes related to cell surface proteins (e.g., CD45 and CD53), and the calcium/calmodulin dependent protein kinase II were upregulated in wt TMT-treated mice, but not in p50-null mice. Overall, this profile further supports the role of NFkB in their regulation. Interestingly, the array results showed that the up-regulation of genes related to survival and brain repair is still upregulated in the late phases of TMT-induced granule cell death in mice.

Taken together, the results obtained in gene expression profiling studies performed in mice appear to homogeneously support current hypotheses on the main pathogenic mechanisms involved in TMT-induced acute granule cell death: alteration of calcium homeostasis, apoptosis and neuroinflammation. Genes associated with the tissue reaction (glial activation and neurogenesis) are also clearly activated (Figure 1a). A central role of neuron/microglial interactions emerges in driving neuroinflammatory signals leading to TMT-induced neuronal death. In addition, data from SGZ studies further support the role exerted by microglial cells on injury-induced neurogenesis $[10,62,63]$.

It is noteworthy in this regard that the stimulation of repair mechanisms has been described in both early and late phases of TMT-induced granule cell death [23,24]. This finding suggests that the mouse model could be suitable to study the molecular mechanisms involved in brain-injury associated with neuroreparative processes, occurring in different temporal frames.

\subsection{The Rat Model}

After TMT administration, rats develop extensive lesions in the CA, typically localized in the CA3/Hilus and also involving CA1, while granular neurons in the DG are generally spared $[1,28]$. Neuronal death shows a delayed onset (two days after treatment) and progressively worsens: it develops over three weeks $[7,8,17]$, probably on account of the high affinity of rat hemoglobin for TMT [17,29], involving CA3 earlier and more severely than CA1 [12,64].

In addition, it occurs in pyramidal cells, with selective sparing of Parvalbumin and Calretinin interneurons, both in adult and in developing rats [65-67]. Also, in the rat model, early astroglial $[28,68,69]$ and microglial activation $[58,70,71]$ are always associated to TMT-induced neuronal death. Thus, the early molecular events, playing a causative role in pyramidal neuronal death, may be different in the two rodent species. The two studies performed on gene expression profiling on the rat model $[25,26]$ evaluated two time points in the early phases of TMT-induced neurodegeneration (see Table 1). The authors explored earlier time points, specifically two to three days after treatment [25,26], corresponding to the earlier evidence of neuronal death [28]. They also analyzed the molecular profile five days after intoxication, when hippocampal neuronal death, reactive astrocytosis and activation of microglia are well established [32,72]. Morita and colleagues did not show microarray results at the two to three day time point, but only the fold changes of differential gene expression confirmed by quantitative reverse transcriptase polymerase chain reaction (qRT-PCR). They validated only those genes whose expression changed after TMT and FK-506 coadministration, as their aim was to evaluate the neuroprotective role of this drug against TMT-induced neurodegeneration [25]. 
Figure 1. A schematic representation of TMT-induced gene activation in (a) mice; (b) rats; and (c) PC12 cells. (a) Results obtained in mice indicate the significant and early involvement of genes related to apoptosis, neuroinflammation and neurogenesis; (b) The studies performed in the rat model reflect an involvement of calcium homeostasis dysregulation and mitochondrial damage. The contribution of the authophagic pathway may be hypothesized, but genes related to neuroinflammation are not unambiguously modulated in the early phases of TMT-induced neurodegeneration; and (c) the study performed in PC12 cells evidences the activation of oxidative metabolism of glucose, cholesterol and fatty acids, along with the early activation of genes involved in apoptosis and stress-related pathways.

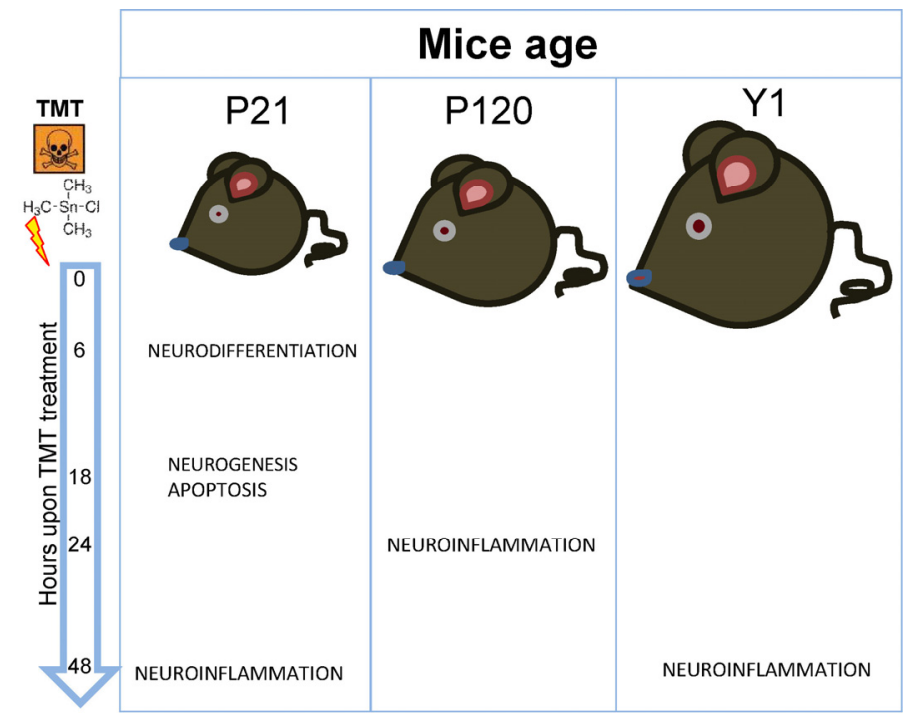

(a)

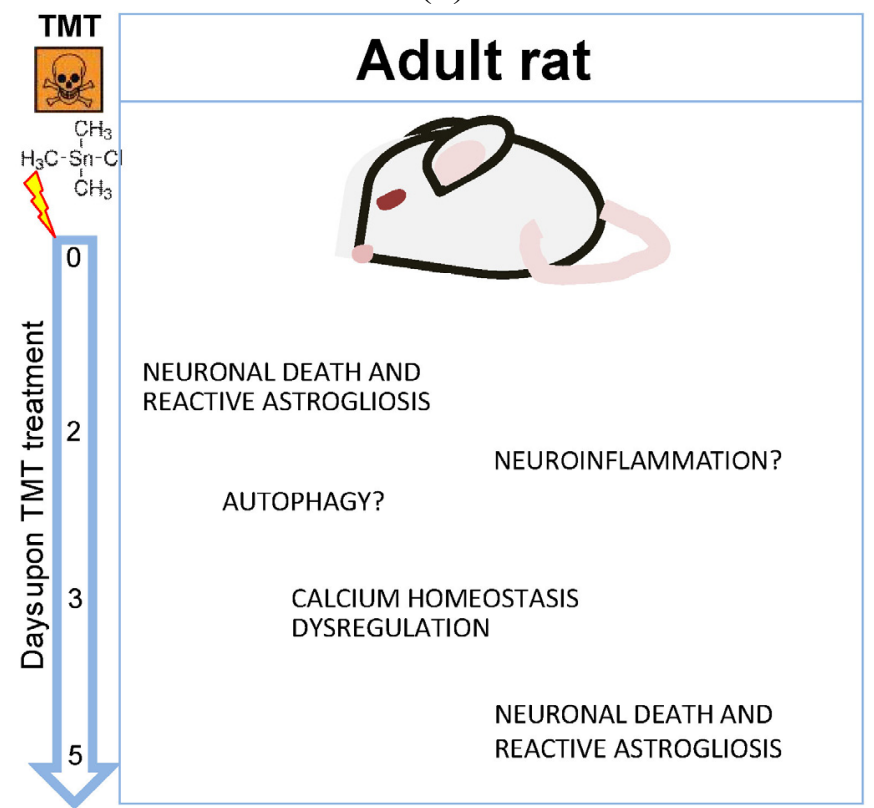

(b) 
Figure 1. Cont.

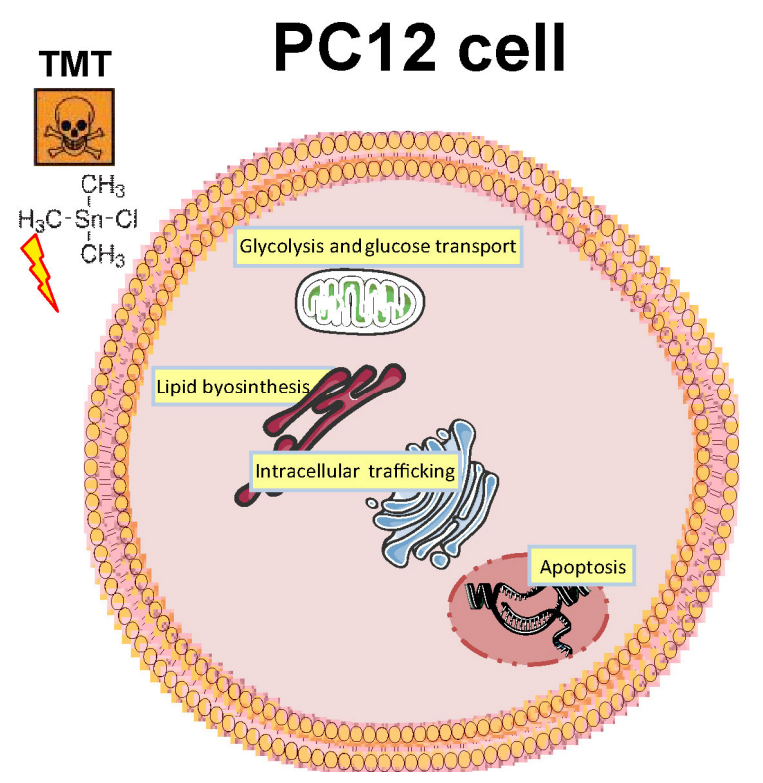

(c)

The study by Little and colleagues [26] pointed out interesting data related to the first time point examined. The authors stressed the activation of genes involved in astroglial activation, such as those related to the glial proteins GFAP and 14-3-3, which, along with the down regulation of $S N A P 25$, may suggest loss of synapses. The decreased expression of cell structure genes, such as tubulin and MAP1B, essentially reflects the phenomena of neuronal loss and astrocytic reaction, occurring at hippocampal level.

Moreover, this study confirmed at the transcriptional level the role exerted by mitochondrial damage in TMT-induced neuronal death, as already indicated by previous data $[20,46]$.

Intriguingly, a relevant group of genes modulated in the early phases of neurodegeneration [26] - in particular, the lysosomal membrane protein LAMP1, Presenilin (PS) 1, 14-3-3, RAB8B and the heat shock protein of $90 \mathrm{kDa}$ chaperone complex (HSP90) — are also involved in the autophagic pathway [72-76], which has recently been suggested to play a role in TMT-intoxication [77]. It is known that autophagy is involved in the degradation of protein aggregates and damaged organelles, among which damaged mitochondria and alterations of autophagy can even lead to neuronal death [78].

The modulation of ubiquitin proteasome related genes, as well as clathrin, both involved in exosomes protein selection machinery [79], might also suggest a modulation of exosome signaling in the injured hippocampus, giving rise to new cues for further investigation.

In addition, the involvement of LAMP1 and both PS1 and PS2 [26] in intracellular $\mathrm{Ca}^{2+}$ homeostasis $[80,81]$ appears to be in line with the hypothesis that TMT-induced neuronal damage could be largely dependent on calcium homeostasis dysregulation [82-85].

Data from Morita and colleagues [25], though not discussed by the authors and reported only at the later time point examined, support this observation. In fact, a modulation of other genes related to calcium signaling, such as preprocathepsin and cathepsin $D$ (upregulated) and the vesicle associated calmodulin binding protein, and calcineurin, downstream target of the $\mathrm{Ca}^{2+}$-calmodulin complex (downregulated) [86], is also reported. A downregulation of Cadherin EGF LAG seven path G-type receptor (Flamingo) gene, a type of non-classical cadherin molecule [87], is also observed in this study. 
$N F k B$ gene appeared to be downregulated in the early phases of TMT-induced neuronal damage in the study by Little and colleagues [26], although the overexpression of the pro survival NFkB p50 protein subunit was previously demonstrated by immunohistochemistry in the rat hippocampus two to seven days after TMT-treatment [88]. The authors associated this event primarily to the absence of early activations of inflammatory mediators, concluding that, in the rat model, neuroinflammation does not play a causative role in initiating neuronal death.

The results by Little and colleagues are not in agreement with those by Morita and colleagues, who found a significant upregulation of some genes associated with the inflammatory response, including Matrix Gla protein gene, lysozyme and osteopontin, though failing in detecting changes in the expression of inflammatory markers (e.g., IL-1alpha and TNFalpha). In particular, osteopontin acts in many tissues as a critical cytokine for macrophage recruitment and activation during cell-mediated immunity [89]. Interestingly, osteopontin has also been found to be upregulated in degenerating neurons in other models of epilepsy [90]. This study also supports the role of oxidative stress-related cell death, through the upregulation of anti-glutathione $S$ transferase [25], both two and five days after TMT-treatment. The expression of both inflammatory and oxidative stress-related genes is further increased five days after TMT-treatment and, interestingly, it is reversed by FK-506 administration [25].

Although the results on neuroinflammation may appear conflicting, it is interesting to note that, in the rat model of TMT-induced neurodegeneration, the early expression of neuroinflammatory mediators has been described both in vitro [91] and in vivo [92]. In addition, the astroglial expression of IL-1alpha and IL-1beta [93], Cyclooxygenase-2 [94] and proteinase activated receptors 1 and 2 [69] have been reported at later time points (14 days post treatment). Since in the mouse model the expression of neuroinflammatory mediators was essentially described to occur in microglia [95], this observation further evidences a difference in the cellular source, which may contribute to the species' difference.

In addition, we might speculate that neuroinflammation, which plays a causative role in granular neurons death in the mouse model of TMT-induced neurodegeneration, exhibits a different temporal profile in the rat model. Further studies would be needed to better clarify the specific role of neuroinflammation in the worsening of the ongoing hippocampal degeneration in rats.

Both Little's and Morita's studies report an upregulation of genes related to the insulin growth factor (IGF) pathway (respectively, IGF receptor 2 and insulin-like growth factor binding protein-2) starting at the earliest time points of TMT-induced hippocampal damage and detectable also five days later [25]. Blood IGF1 and IGF2 levels exert trophic effects on neurogenesis and neuronal survival [96], as already suggested in the mouse model [97]; it has also been recently shown that cultured human microglia are significant sources of IGF1 and IGF2 that can be modulated by inflammatory cytokines [98].

Data regarding the second time point explored in the two above mentioned studies [25,26] (5 days after TMT-administration) essentially reflect the events characterizing the neuropathological features of TMT-induced lesion at this time point post-treatment (neuronal loss and glial activation). The authors describe an increased expression of genes considered markers for activation of microglia (CCL2, MHC-I and MHCII), astroglia (GFAP, vimentin, glutamine synthetase and peripheral benzodiazepine receptor), and genes related to neurodegeneration such as PS2, $\beta$-catenin, and Tau. In line with these findings, Morita et al. [25] refers to an increase of $S 100$ related protein mRNA, possibly linked to the developing astroglial reaction, and a downregulation of genes related to 
neurotransmission and synaptic function, such as Synaptotagmin XI [99], Synaphin 2 [100] and synaptic cell adhesion molecule 1 [101]. These data, along with the expression changes of the GABA transporter alanine-sensitive protein [102] and of the neuropeptide $Y$ gene [25], may reflect the loss of synapses and neurotransmitter alterations related to seizures, neuronal loss and related plasticity changes [17].

Taken together, the information coming from gene expression studies performed in the rat model reflects a more heterogeneous scenario, when compared with those derived from mice. An involvement of calcium homeostasis dysregulation, as well as mithocondrial damage, are clearly indicated (Figure 1b). The contribute of the authophagic pathway may be hypothesized, while genes related to neuroinflammation appear not to be unambiguously modulated in the early phases of TMT-induced neurodegeneration in rats, and a definite molecular pathway playing a causative role in pyramidal neurons death does not seem to emerge in the reported data.

This could be due to many factors. The processes underlying neurodegenerative phenomena occurring in mice and rats may reasonably be different, the first being an acute phenomenon, while neurodegeneration occurring in rats may be regarded as a chronic phenomenon. In addition, as the onset of neuronal death may delay two to four days after treatment [28], individual differences among treated rats are possible and a larger group of animals could be needed to achieve conclusive results.

Moreover, the examined specimens (whole hippocampi) are reflective of an heterogeneous cell population (neurons and glia), and slight differences in the expression of genes involved in different pathways, possibly leading to opposite effects (neuronal death versus neuroreparative processes), may be underestimated in these conditions.

In addition, differences in rat strains, in the dosage schedule and route of administration used in the different studies (see Table 1) should be taken into account and may explain some of the observed discrepancies.

\subsection{The Cell Culture Model}

Cell cultures offer a simplified model to study molecular mechanisms, as they allow examining a more homogeneous system, although they lack information deriving from cell-cell interaction and from microenvironment of the in vivo tissue. Thus, an in vitro model to study cell events leading to death upon TMT intoxication has been proposed using a homogenous cell line, the rat pheocromocytoma PC12 cells, commonly used for studying cell proliferation, neurotoxicity and cell death. The results obtained in this study demonstrated that sub-lethal concentrations of TMT induce adaptive mechanisms in the cell, through the activation of oxidative metabolism of glucose, cholesterol and fatty acids, along with the early activation of genes involved in apoptosis and stress-related pathways [27] (Figure 1c). Also, the intracellular trafficking was apparently activated while calcium transport was not evidently involved in this model, except for the upregulation of two genes (calumenin and reticulocalbin 3). A possible keystone to interpret the concurrent activation of metabolic and injury-related signaling is represented by a response to hypoxic stimulus. In fact, many genes in the gene list were targets of the transcription factor encoded by the hypoxia-inducible gene 1 (Hifl $\alpha$ ), which was among the upregulated genes. HIF1 $\alpha$ represents a key factor of hypoxia-related intracellular reactions, as it generates adaptive responses by inducing the expression of various target 
genes involved in proliferation, glucose metabolism and transport [103]. On the other hand, the same molecule may induce apoptosis through the activation of cytokines, such as Bnip3 (also upregulated in PC12 cells upon TMT treatment), which cause mithocondrial dysfunction [20,27,103]. HIF1 $\alpha$ has also been recently shown to modulate the proliferation/differentiation switch in neural stem and progenitor cells, in response to hypoxic and hypoxic-like noxae to the niche [104]. Interestingly, the metabolic profile observed in TMT-intoxicated cells indicates the overall activation of lipid biogenesis [27], which may reflect the known effects of organotin compounds on plasma membrane composition, plasticity and permeability [105-108]. Besides the pro-apoptotic effects, TMT seems to also induce autophagic cell death in PC12 cells, as suggested by the activation of selected genes (namely Bnip3, Bnip3-like and adrenomedullin) [27].

\section{Concluding Remarks and Perspectives}

Some general considerations may emerge when searching for common features in the molecular profiles associated to the different models studied, although it is difficult to compare or combine the results obtained from the microarray analysis, due to substantial differences in sample composition, tissue sources, and methodologies. As a rule, the consistency of microarray data largely depends on sample dimension and heterogeneity [109-112]. Such general observations perfectly apply to the case of microarray studies performed in the different TMT models that are characterized by relevant differences in the biological and technical features of the experimental protocols.

As expected, the different studies confirm the critical role played by mitochondrial dysfunction and disruption of $\mathrm{Ca}^{2+}$ homeostasis in the early phases of TMT-induced neuronal death [24,26,27].

Moreover, the different models share data on the modulation of genes involved in the autophagic pathway, such as those encoding lysosomal enzymes (e.g., beta-glicuronidase, cathepsin C and D, LAMP1) [25,26,53], SNARE protein genes [25] and lipid biogenesis [27], thus suggesting a possible role played by this pathway in TMT-induced neuronal death. Interestingly, it has been proposed that autophagy is involved in neurodegeneration through the inactivation of NFkB [113], which has been shown to be involved in TMT-induced neuronal death $[18,24,54,55]$. In conclusion, as TMT activates different pathogenic mechanisms leading to cell death, the approach based on gene profiling examination appears to be promising, since it provides a comprehensive snapshot of the molecular scenario. Nonetheless, further studies are needed to achieve a convincing functional validation of the specific role and possible intersection of the signaling cascades triggered by TMT administration and leading to selective neuronal death.

\section{Acknowledgments}

This work was partially supported by funds from Università Cattolica del S. Cuore to F.M., M.C.G. and W.L.

\section{Conflicts of Interest}

The authors declare no conflict of interest. 


\section{References}

1. Chang, L.W.; Wenger, G.R.; McMillan, D.E.; Dyer, R.S. Species and strain comparison of acute neurotoxic effects of trimethyltin in mice and rats. Neurobehav. Toxicol. Teratol. 1983, 5, 337-350.

2. Chang, L.W. The neurotoxicology and pathology of organomercury, organolead, and organotin. J. Toxicol. Sci. Suppl. 1990, 4, 125-151.

3. Boyer, I.J. Toxicity of dibutyltin, tributyltin and other organotin compounds to humans and to experimental animals. Toxicology 1989, 55, 253-298.

4. Jiang, G.B.; Zhou, Q.F.; He, B. Tin compounds and major trace metal elements in organotin poisoned patient's urine and blood measured by gas chromatography flame photometric detector and inductively coupled plasma mass spectrometry. Bull. Environ. Contam. Toxicol. 2000, 65, 277-284.

5. Saary, M.J.; House, R.A. Preventable exposure to trimethyltin chloride: A case report. Occup. Med. 2002, 52, 227-230.

6. Yoo, C.I.; Kim, Y.; Jeong, K.S.; Sim, C.S.; Choy, N.; Kim, J.; Eum, J.B.; Nakaiama, Y.; Endo, Y.; Kim, Y.J. A case of acute organotin poisoning. J. Occup. Health 2007, 49, 305-310.

7. Geloso, M.C.; Corvino, V.; Michetti, F. Trimethyltin-induced hippocampal degeneration as a tool to investigate neurodegenerative processes. Neurochem. Int. 2011, 58, 729-738.

8. Corvino, V.; Marchese, E.; Michetti, F.; Geloso, M.C. Neuroprotective strategies in hippocampal neurodegeneration induced by the neurotoxicant trimethyltin. Neurochem. Res. 2013, 38, 240-253.

9. Ogita, K.; Nishiyama, N.; Sugiyama, C.; Higuchi, K.; Yoneyama, M.; Yoneda, Y. Regeneration of granule neurons after lesioning of hippocampal dentate gyrus: Evaluation using adult mice treated with trimethyltin chloride as a model. J. Neurosci. Res. 2005, 82, 609-621.

10. McPherson, C.A.; Aoyama, M.; Harry, G.J. Interleukin (IL)-1 and IL-6 regulation of neural progenitor cell proliferation with hippocampal injury: Differential regulatory pathways in the subgranular zone (SGZ) of the adolescent and mature mouse brain. Brain Behav. Immun. 2011, $25,850-862$.

11. Corvino, V.; Geloso, M.C.; Cavallo, V.; Guadagni, E.; Passalacqua, R.; Florenzano, F.; Giannetti, S.; Molinari, M.; Michetti, F. Enhanced neurogenesis during trimethyltin-induced neurodegeneration in the hippocampus of the adult rat. Brain Res. Bull. 2005, 65, 471-477.

12. Corvino, V.; Marchese, E.; Giannetti, S.; Lattanzi, W.; Bonvissuto, D.; Biamonte, F.; Mongiovì, A.M.; Michetti, F.; Geloso, M.C. The neuroprotective and neurogenic effects of neuropeptide $\mathrm{Y}$ administration in an animal model of hippocampal neurodegeneration and temporal lobe epilepsy induced by trimethyltin. J. Neurochem. 2012, 122, 415-426.

13. Harry, G.J.; Lefebvre d'Hellencourt, C. Dentate gyrus: Alterations that occur with hippocampal injury. Neurotoxicology 2003, 24, 343-356.

14. Little, A.R.; Benkovic, S.A.; Miller, D.B.; O’Callaghan, J.P. Chemically induced neuronal damage and gliosis: Enhanced expression of the proinflammatory chemokine, monocyte chemoattractant protein (MCP)-1, without a corresponding increase in proinflammatory cytokines. Neuroscience 2002, 115, 307-320. 
15. Funk, J.A.; Gohlke, J.; Kraft, A.D.; McPherson, C.A.; Collins, J.B.; Harry, G.J. Voluntary exercise protects hippocampal neurons from trimethyltin injury: Possible role of interleukin-6 to modulate tumor necrosis factor receptor mediated neurotoxicity. Brain Behav. Immun. 2011, 25, 1063-1077.

16. Kraft, A.D.; Harry, G.J. Features of microglia and neuroinflammation relevant to environmental exposure and neurotoxicity. Int. J. Environ. Res. Public Health 2011, 8, 2980-3018.

17. Koczyk, D. How does trimethyltin affect the brain: Facts and hypotheses. Acta Neurobiol. Exp. (Wars) 1996, 56, 587-596.

18. Florea, A.M.; Büsselberg, D. Anti-cancer drugs interfere with intracellular calcium signaling. Neurotoxicology 2009, 30, 803-810.

19. Aldrige, W.N.; Street, B.W.; Skilleter, D.N. Oxidative phosphorylation. Halide-dependent and halide-independent effects of triorganotin and triorganolead compounds on mitochondrial functions. Biochem. J. 1977, 168, 353-364.

20. Misiti, F.; Orsini, F.; Clementi, M.E.; Lattanzi, W.; Giardina, B.; Michetti, F. Mitochondrial oxygen consumption inhibition importance for TMT-dependent cell death in undifferentiated PC12 cells. Neurochem. Int. 2008, 52, 1092-1099.

21. Billingsley, M.L.; Yun, J.; Reese, B.E.; Davidson, C.E.; Buck-Koehntop, B.A.; Veglia, G. Functional and structural properties of stannin: Roles in cellular growth, selective toxicity, and mitochondrial responses to injury. J. Cell. Biochem. 2006, 98, 243-250.

22. Vrana, K.E.; Freeman, W.M.; Aschner, M. Use of microarray technologies in toxicology research. Neurotoxicology 2003, 24, 321-332.

23. Kassed, C.A.; Butler, T.L.; Patton, G.W.; Demesquita, D.D.; Navidomskis, M.T.; Mémet, S.; Israël, A.; Pennypacker, K.R. Injury-induced NF- $\kappa B$ activation in the hippocampus: Implications for neuronal survival. FASEB J. 2004, 18, 723-724.

24. Lefebvre d'Hellencourt, C.; Harry, G.J. Molecular profiles of mRNA levels in laser capture microdissected murine hippocampal regions differentially responsive to TMT-induced cell death. J. Neurochem. 2005, 93, 206-220.

25. Morita, M.; Imai, H.; Liu, Y.; Xu, X.; Sadamatsu, M.; Nakagami, R.; Shirakawa, T.; Nakano, K.; Kita, Y.; Yoshida, K.; et al. FK506-protective effects against trimethyltin neurotoxicity in rats: Hippocampal expression analyses reveal the involvement of periarterial osteopontin. Neuroscience 2008, 153, 1135-1145.

26. Little, A.R.; Miller, D.B.; Li, S.; Kashon, M.L.; O’Callaghan, J.P. Trimethyltin-induced neurotoxicity: Gene expression pathway analysis, q-RT-PCR and immunoblotting reveal early effects associated with hippocampal damage and gliosis. Neurotoxicol. Teratol. 2012, 34, 72-82.

27. Lattanzi, W.; Bernardini, C.; Gangitano, C.; Michetti, F. Hypoxia-like transcriptional activation in TMT-induced degeneration: Microarray expression analysis on PC12 cells. J. Neurochem. 2007, 100, 1688-1702.

28. Balaban, C.D.; O'Callaghan, J.P.; Billingsley, M.L. Trimethyltin-induced neuronal damage in the rat brain: Comparative studies using silver degeneration stains, immunocytochemistry and immunoassay for neurotypic and gliotypic proteins. Neuroscience 1988, 26, 337-361.

29. Harry, G.J.; Goodrum, J.F.; Krigman, M.R.; Morell, P. The use of Synapsin I as a biochemical marker for neuronal damage by trimethyltin. Brain Res. 1985, 326, 9-18. 
30. Moser, V.C. Rat strain-and gender-related differences in neurobehavioral screening: Acute trimethyltin neurotoxicity. J. Toxicol. Environ. Health 1996, 47, 567-586.

31. Ishida, N.; Akaike, M.; Tsutsumi, S.; Kanai, A.; Masui, M.; Sadamatsu, Y.; Kuroda, Y.; Watanabe, Y.; McEwen, B.S.; Kato, N. Trimethyltin syndrome as a hippocampal degeneration model: Temporal changes and neurochemical features of seizure susceptibility and learning impairment. Neuroscience 1997, 8, 1183-1191.

32. Brown, A.W.; Aldridge, W.N.; Street, B.W.; Verschoyle, R.D. The behavioural and neuropathologic sequelae of intoxication by trimethyltin compound in the rat. Am. J. Pathol. 1979, 97, 59-81.

33. Ishikawa, K.; Kubo, T.; Shibanoki, S.; Matsumoto, A.; Hata, H.; Asai, S. Hippocampal degeneration inducing impairment of learning in rats: Model of dementia? Behav. Brain Res. 1997, 83, 39-44.

34. Nilsberth, C.; Kostyszyn, B.; Luthman, J. Changes in APP, PS1 and other factors related to Alzheimer's disease pathophysiology after trimethyltin-induced brain lesion in the rat. Neurotox. Res. 2002, 4, 625-636.

35. O’Connell, A.W.; Strada, O.; Earley, B.; Leonard, B.E. Altered expression of amyloid protein precursor mRNA in the rat hippocampus following trimethyltin intoxication: An in situ hybridization study. Neurochem. Int. 1997, 30, 313-320.

36. Woodruff, M.L.; Baisden, R.H. Trimethyltin Neurotoxicity in the Rat as an Analogous Model of Alzheimer's Disease. In Toxin-Induced Models of Neurological Disorders; Woodruff, M.L., Nonneman, A.J., Eds.; Plenum Press: New York, NY, USA, 1994; pp. 319-335.

37. Figiel, I.; Fiedorowicz, A. Trimethyltin-evoked neuronal apoptosis and glia response in mixed cultures of rat hippocampal dentate gyrus: A new model for the study of the cell type-specific influence of neurotoxins. Neurotoxicology 2002, 23, 77-86.

38. Jenkins, S.M.; Barone, S. The neurotoxicant trimethyltin induces apoptosis via caspase activation, p38 protein kinase, and oxidative stress in PC12 cells. Toxicol. Lett. 2004, 147, 63-72.

39. Reali, C.; Scintu, F.; Pillai, R.; Donato, R.; Michetti, F.; Sogos, V. S100b counteracts effects of the neurotoxicant trimethyltin on astrocytes and microglia. J. Neurosci. Res. 2005, 81, 677-686.

40. Aschner, M.; Aschner, J.L. Cellular and molecular effects of trimethyltin and triethyltin: Relevance to organotin neurotoxicity. Neurosci. Biobehav. Rev. 1992, 16, 427-435.

41. Eskes, C.; Juillerat-Jeanneret, L.; Leuba, G.; Honegger, P.; Monnet-Tschudi, F. Involvement of microglia-neuron interactions in the tumor necrosis factor-alpha release, microglial activation, and neurodegeneration induced by trimethyltin. J. Neurosci. Res. 2003, 71, 583-590.

42. Figiel, I.; Dzwonek, K. TNFalpha and TNF receptor 1 expression in the mixed neuronal-glial cultures of hippocampal dentate gyrus exposed to glutamate or trimethyltin. Brain Res. 2007, $1131,17-28$.

43. Gunasekar, P.G.; Mickova, V.; Kotyzova, D.; Li, L.; Borowitz, J.L. Role of astrocytes in trimethyltin neurotoxicity. J. Biochem. Mol. Toxicol. 2001, 15, 256-262.

44. Harry, G.J.; Tyler, K.; d'Hellencourt, C.L.; Tilson, H.A.; Maier, W.E. Morphological alterations and elevations in tumor necrosis factor-alpha, interleukin (IL)-1alpha, and IL-6 in mixed glia cultures following exposure to trimethyltin: Modulation by proinflammatory cytokine recombinant proteins and neutralizing antibodies. Toxicol. Appl. Pharmacol. 2002, 180, 205-218. 
45. Harry, G.J.; Lefebvre d'Hellencourt, C.; McPherson, C.A.; Funk, J.A.; Aoyama, M.; Wine, R.N. Tumor necrosis factor p55 and p75 receptors are involved in chemical-induced apoptosis of dentate granule neurons. J. Neurochem. 2008, 106, 281-298.

46. Thompson, T.A.; Lewis, J.M.; Dejneka, N.S.; Severs, W.B.; Polavarapu, R.; Billingsley, M.L. Induction of apoptosis by organotin compounds in vitro: Neuronal protection with antisense oligonucleotides directed against stannin. J. Pharmacol. Exp. Ther. 1996, 276, 1201-1211.

47. Ekuta, J.E.; Hikal, A.H.; Matthews, J.C. Toxicokinetics of trimethyltin in four inbred strains of mice. Toxicol. Lett. 1998, 95, 41-96.

48. Wenger, G.R.; McMillan, D.E.; Chang, L.W. Behavioral effects of trimethyltin in two strains of mice. II. Multiple fixed ratio, fixed interval. Toxicol. Appl. Pharmacol. 1984, 73, 89-96.

49. Kawada, K.; Yoneyama, M.; Nagashima, R.; Ogita, K.; Kawada, K. In vivo acute treatment with trimethyltin chloride causes neuronal degeneration in the murine olfactory bulb and anterior olfactory nucleus by different cascades in each region. J. Neurosci. Res. 2008, 86, 1635-1646.

50. Fiedorowicz, A.; Figiel, I.; Kaminska, B.; Zeremba, M.; Wilk, S.; Oderfeld-Nowak, B. Dentate granule neuron apoptosis and glia activation in murine hippocampus induced by trimethyltin exposure. Brain Res. 2001, 912, 116-127.

51. Geloso, M.C.; Vercelli, A.; Corvino, V.; Repici, M.E.; Boca, M.; Haglid, K.; Zelano, G.; Michetti, F. Cyclooxygenase-2 and caspase-3 expression in trimethyltin induced apoptosis in the mouse hippocampus. Exp. Neurol. 2002, 175, 152-160.

52. Ito, C.Y.; Adey, N.; Bautch, V.L.; Baldwin, A.S., Jr. Structure and evolution of the human IKBA gene. Genomics 1995, 29, 490-495.

53. Kassed, C.A.; Willing, A.E.; Garbuzova-Davis, S.; Sanberg, P.R.; Pennypacker, K.R. Lack of NF- $\kappa$ B p50 exacerbates degeneration of hippocampal neurons after chemical exposure and impairs learning. Exp. Neurol. 2002, 176, 277-288.

54. Qing, Y.; Liang, Y.; Du, Q.; Fan, P.; Xu, H.; Xu, Y.; Shi, N. Apoptosis induced by Trimethyltin chloride in human neuroblastoma cells SY5Y is regulated by a balance and cross-talk between NF-кB and MAPKs signaling pathways. Arch. Toxicol. 2013, 87, 1273-1285.

55. Zhang, L.; Li, L.; Prabhakaran, K.; Borowitz, J.L.; Isom, G.E. Trimethyltin-induced apoptosis is associated with upregulation of inducible nitric oxide synthase and Bax in a hippocampal cell line. Toxicol. Appl. Pharmacol. 2006, 216, 34-43.

56. Shohami, E.; Ginis, I.; Hallenbeck, J.M. Dual role of tumor necrosis factor alpha in brain injury. Cytokine Growth Factor Rev. 1999, 10, 119-130.

57. Maier, W.E.; Brown, H.W.; Tilson, H.A.; Luster, M.I.; Harry, G.J. Trimethyltin increases interleukin (IL)-1 $\alpha$, IL-6 and tumor necrosis factor $\alpha$ mRNA levels in rat hippocampus. J. Neuroimmunol. 1995, 59, 65-75.

58. Teocchi, M.A.; Ferreira, A.É.; da Luz de Oliveira, E.P.; Tedeschi, H.; D’Souza-Li, L. Hippocampal gene expression dysregulation of Klotho, nuclear factor kappa B and tumor necrosis factor in temporal lobe epilepsy patients. J. Neuroinflammation 2013, 10, doi:10.1186/1742-2094-10-53.

59. Yang, J.; Chatterjee-Kishore, M.; Staugaitis, S.M.; Nguyen, H.; Schlessinger, K.; Levy, D.E.; Stark, G.R. Novel roles of unphosphorylated STAT3 in oncogenesis and transcriptional regulation. Cancer Res. 2005, 65, 939-947. 
60. Rowley, M.; van Ness, B. Activation of N-ras and K-ras induced by interleukin-6 in a myeloma cell line: Implications for disease progression and therapeutic response. Oncogene 2002, 21, 8769-8775.

61. Reich, N.C. STAT dynamics. Cytokine Growth Factor Rev. 2007, 18, 511-518.

62. McPherson, C.A.; Kraft, A.D.; Harry, G.J. Injury-induced neurogenesis: Consideration of resident microglia as supportive of neural progenitor cells. Neurotox. Res. 2011, 19, 341-352.

63. Harry, G.J. Microglia during development and aging. Pharmacol. Ther. 2013, 139, 313-326.

64. Latini, L.; Geloso, M.C.; Corvino, V.; Giannetti, S.; Florenzano, F.; Viscomi, M.T.; Michetti, F.; Molinari, M. Trimethyltin intoxication up-regulates nitric oxide synthase in neurons and purinergic ionotropic receptor 2 in astrocytes in the hippocampus. J. Neurosci. Res. 2010, 88, 500-509.

65. Geloso, M.C.; Vinesi, P.; Michetti, F. Parvalbumin-immunoreactive neurons are not affected by trimethyltin-induced neurodegeneration in the rat hippocampus. Exp. Neurol. 1996, 139, 269-277.

66. Geloso, M.C.; Vinesi, P.; Michetti, F. Calretinin-containing neurons in trimethyltin-induced neurodegeneration in the rat hippocampus: An immunocytochemical study. Exp. Neurol. 1997, 146, 67-73.

67. Geloso, M.C.; Vinesi, P.; Michetti, F. Neuronal subpopulations of developing rat hippocampus containing different calcium-binding proteins behave distinctively in trimethyltin-induced neurodegeneration. Exp. Neurol. 1998, 154, 645-653.

68. Geloso, M.C.; Corvino, V.; Cavallo, V.; Toesca, A.; Guadagni, E.; Passalacqua, R.; Michetti, F. Expression of astrocytic nestin in the rat hippocampus during trimethyltin-induced neurodegeneration. Neurosci. Lett. 2004, 357, 103-106.

69. Pompili, E.; Nori, S.L.; Geloso, M.C.; Guadagni, E.; Corvino, V.; Michetti, F.; Fumagalli, L. Trimethyltin-induced differential expression of PAR subtypes in reactive astrocytes of the rat hippocampus. Brain Res. Mol. Brain Res. 2004, 122, 93-98.

70. Brabeck, C.; Michetti, F.; Geloso, M.C.; Corvino, V.; Goezalan, F.; Meyermann, R.; Schluesener, H.J. Expression of EMAP-II by activated monocytes/microglial cells in different regions of the rat hippocampus after trimethyltin-induced brain damage. Exp. Neurol. 2002, 177, 341-346.

71. Pompili, E.; Fabrizi, C.; Nori, S.L.; Panetta, B.; Geloso, M.C.; Corvino, V.; Michetti, F.; Fumagalli, L. Protease-activated receptor-1 expression in rat microglia after trimethyltin treatment. J. Histochem. Cytochem. 2011, 59, 302-311.

72. Brock, T.O.; O'Callaghan, J.P. Quantitative changes in the synaptic vesicle proteins synapsin I and p38 and the astrocyte-specific protein glial fibrillary acidic protein are associated with chemical-induced injury to the rat central nervous system. J. Neurosci. 1987, 7, 931-942.

73. Pilli, M.; Arko-Mensah, J.; Ponpuak, M.; Roberts, E.; Master, S.; Mandell, M.A.; Dupont, N.; Ornatowski, W.; Jiang, S.; Bradfute, S.B.; et al. TBK-1 promotes autophagy-mediated antimicrobial defense by controlling autophagosome maturation. Immunity 2012, 37, 223-234.

74. Steinacker, P.; Aitken, A.; Otto, M. 14-3-3 proteins in neurodegeneration. Semin. Cell Dev. Biol. 2011, 22, 696-704.

75. Yamashima, T. Reconsider Alzheimer's disease by the 'calpain-cathepsin hypothesis'A perspective review. Prog. Neurobiol. 2013, 105, 1-23. 
76. Wang, B.; Ling, S.; Lin, W.C. 14-3-3T regulates Beclin 1 and is required for autophagy. PLoS One 2010, 5, e10409.

77. Fabrizi, C.; Somma, F.; Pompili, E.; Biagioni, F.; Lenzi, P.; Fornai, F.; Fumagalli, L. Role of autophagy inhibitors and inducers in modulating the toxicity of trimethyltin in neuronal cell cultures. J. Neural Transm. 2012, 119, 1295-1305.

78. Viscomi, M.T.; D'Amelio, M. The "Janus-faced role" of autophagy in neuronal sickness: Focus on neurodegeneration. Mol. Neurobiol. 2012, 46, 513-521.

79. Stoorvogel, W.; Kleijmeer, M.J.; Geuze, H.J.; Raposo, G. The biogenesis and functions of exosomes. Traffic 2002, 3, 321-330.

80. McCue, H.V.; Wardyn, J.D.; Burgoyne, R.D.; Haynes, L.P. Source generation and characterization of a lysosomally targeted, genetically encoded $\mathrm{Ca}^{2+}$-sensor. Biochem. J. 2013, 49, 449-457.

81. Kipanyula, M.J.; Contreras, L.; Zampese, E.; Lazzari, C.; Wong, A.K.; Pizzo, P.; Fasolato, C.; Pozzan, T. $\mathrm{Ca}^{2+}$ dysregulation in neurons from transgenic mice expressing mutant presenilin 2. Aging Cell 2012, 11, 885-893.

82. Florea, A.; Elke, D.; Busselberg, D. Elevated $\mathrm{Ca}^{2+}$ transients induced by trimethyltin chloride in HeLa cells: Types and levels of response. Cell Calcium 2005, 37, 251-258.

83. Florea, A.M.; Splettstoesser, F.; Dopp, E.; Rettenmeier, A.W.; Busselberg, D. Modulation of intracellular calcium homeostasis by trimethyltin chloride in human tumour cells: Neuroblastoma SY5Y and cervix adenocarcinoma HeLaS3. Toxicology 2005, 216, 1-8.

84. Piacentini, R.; Gangitano, C.; Ceccariglia, S.; Del Fà, A.; Azzena, G.B.; Michetti, F.; Grassi, C. Dysregulation of intracellular calcium homeostasis is responsible for neuronal death in an experimental model of selective hippocampal degeneration induced by trimethyltin. J. Neurochem. 2008, 105, 2109-2121.

85. Ceccariglia, S.; D’Altocolle, A.; Del Fà, A.; Pizzolante, F.; Caccia, E.; Michetti, F.; Gangitano, C. Cathepsin D plays a crucial role in the trimethyltin-induced hippocampal neurodegeneration process. Neuroscience 2011, 174, 160-170.

86. Shibasaki, F.; Hallin, U.; Uchino, H. Calcineurin as a multifunctional regulator. J. Biochem. 2002, 131, 1-15.

87. Usui, T.; Shima, Y.; Shimada, Y.; Hirano, S.; Burgess, R.W.; Schwarz, T.L.; Takeichi, M.; Uemura, T. Flamingo, a seven-pass transmembrane cadherin, regulates planar cell polarity under the control of Frizzled. Cell 1999, 98, 585-595.

88. Pennypacker, K.R.; Kassed, C.A.; Eidizadeh, S.; Saporta, S.; Sanberg, P.R.; Willing, A.E. NF-кB p50 is increased in neurons surviving hippocampal injury. Exp. Neurol. 2001, 172, 307-319.

89. Denhardt, D.T.; Noda, M.; O’Regan, A.W.; Pavlin, D.; Berman, J.S. Osteopontin as a means to cope with environmental insults: Regulation of inflammation, tissue remodeling, and cell survival. J. Clin. Invest. 2001, 107, 1055-1061.

90. Borges, K.; Gearing, M.; Rittling, S.; Sorensen, E.S.; Kotloski, R.; Denhardt, D.T.; Dingledine, R. Characterization of osteopontin expression and function after status epilepticus. Epilepsia 2008, 49, 1675-1685.

91. Jahnke, G.D.; Brunssen, S.; Maier, W.E.; Harry, G.J. Neurotoxicant-induced elevation of adrenomedullin expression in hippocampus and glia cultures. J. Neurosci. Res. 2001, 66, 464-474. 
92. Harry, G.J.; Sills, R.; Schlosser, M.J.; Maier, W.E. Neurodegeneration and glia response in rat hippocampus following nitro-L-arginine methyl ester (L-NAME). Neurotox. Res. 2001, 3, 307-319.

93. Liu, Y.; Imai, H.; Sadamatsu, M.; Tsunashima, K.; Kato, N. Cytokines participate in neuronal death induced by trimethyltin in the rat hippocampus via type II glucocorticoid receptors. Neurosci. Res. 2005, 51, 319-327.

94. Corvino, V.; Marchese, E.; Zarkovic, N.; Zarkovic, K.; Cindric, M.; Waeg, G.; Michetti, F.; Geloso, M.C. Distribution and timecourse of 4-hydroxynonenal, heat shock protein 110/105 family members and cyclooxygenase-2 expression in the hippocampus of rat during trimethyltin-induced neurodegeneration. Neurochem. Res. 2011, 36, 1490-1500.

95. Bruccoleri, A.; Brown, H.; Harry, G.J. Cellular localization and temporal elevation of tumor necrosis factor-alpha, interleukin-1 alpha, and transforming growth factor-beta $1 \mathrm{mRNA}$ in hippocampal injury response induced by trimethyltin. J. Neurochem. 1998, 71, 1577-1587.

96. Zhuang, S. Regulation of STAT signaling by acetylation. Cell. Signal. 2013, 25, 1924-1931.

97. Wine, R.N.; McPherson, C.A.; Harry, G.J. IGF-1 and pAKT signaling promote hippocampal CA1 neuronal survival following injury to dentate granule cells. Neurotox. Res. 2009, 16, 280-292.

98. Suh, H.S.; Zhao, M.L.; Derico, L.; Choi, N.; Lee, S.C. Insulin-like growth factor 1 and 2 (IGF1, IGF2) expression in human microglia: Differential regulation by inflammatory mediators. J. Neuroinflammation 2013, 10, doi:10.1186/1742-2094-10-37.

99. Rizo, J.; Chen, X.; Arac, D. Unraveling themechanisms of synaptotagmin and SNARE function in neurotransmitter release. Trends Cell Biol. 2006, 16, 339-350.

100. Ishizuka, T.; Saisu, H.; Odani, S.; Abe, T. Synaphin: A protein associated with the docking/fusion complex in presynaptic terminal. Biochem. Biophys. Res. Commun. 1995, 213, 1107-1114.

101. Baumgartner, W.; Osmanagic, A.; Gebhard, M.; Kraemer, S.; Golenhofen, N. Different $\mathrm{pH}$-dependencies of the two synaptic adhesion molecules $N$-cadherin and cadherin-11 and the possible functional implication for long term potentiation. Synapse 2013, doi:10.1002/syn.21679.

102. Guimbal, C.; Klostermann, A.; Kilimann, M.W. Phylogenetic conservation of 4-aminobutyric acid [GABA] transporter isoforms. Cloning and pharmacological characterization of a GABA/ $\beta$-alanine transporter from Torpedo. Eur. J. Biochem. 1995, 234, 794-800.

103. Singh, N.; Sharma, G.; Mishra, V. Hypoxia inducible factor-1: Its potential role in cerebral ischemia. Cell. Mol. Neurobiol. 2012, 32, 491-507.

104. Cunningham, L.A.; Candelario, K.; Li, L. Roles for HIF-1 $\alpha$ in neural stem cell function and the regenerative response to stroke. Behav. Brain Res. 2012, 227, 410-417.

105. Harkins, A.B.; Armstrong, D.L. Trimethyltin alters membrane properties of CA1 hippocampal neurons. Neurotoxicology 1992, 13, 569-581.

106. Chow, S.C.; Orrenius, S. Rapid cytoskeleton modification in thymocytes induced by the immunotoxicant tributyltin. Toxicol. Appl. Pharmacol. 1994, 127, 19-26.

107. Richter-Landsberg, C.; Besser, A. Effects of organotins on rat brain astrocytes in culture. J. Neurochem. 1994, 63, 2202-2209.

108. Ortiz, A.; Teruel, J.A.; Aranda, F.J. Effect of triorganotin compounds on membrane permeability. Biochim. Biophys. Acta 2005, 1720, 137-142. 
109. Bernardini, C.; Barba, M.; Tamburrini, G.; Massimi, L.; di Rocco, C.; Michetti, F.; Lattanzi, W. Gene expression profiling in human craniosynostoses: A tool to investigate the molecular basis of suture ossification. Childs Nerv. Syst. 2012, 28, 1295-1300.

110. Bernardini, C.; Censi, F.; Lattanzi, W.; Barba, M.; Calcagnini, G.; Giuliani, A.; Tasca, G.; Sabatelli, M.; Ricci, E.; Michetti, F. Mitochondrial network genes in the skeletal muscle of amyotrophic lateral sclerosis patients. PLoS One 2013, 8, e57739.

111. Bernardini, C.; Lattanzi, W.; Bosco, P.; Franceschini, C.; Plazzi, G.; Michetti, F.; Ferri, R. Genome-wide gene expression profiling of human narcolepsy. Gene Expr. 2012, 15, 171-181.

112. Bernardini, C.; Lattanzi, W.; Businaro, R.; Leone, S.; Corvino, V.; Sorci, G.; Lauro, G.; Fumagalli, L.; Donato, F.R.; Michetti, F. Transcritpional effects of S100B on neuroblastoma cells: Perturbation of cholesterol homeostasis and interference on the cell cycle. Gene Expr. 2010, 14, 345-359.

113. Xiao, G. Autophagy and NF-кB: Fight for fate. Cytokine Growth Factor Rev. 2007, 18, 233-243.

(C) 2013 by the authors; licensee MDPI, Basel, Switzerland. This article is an open access article distributed under the terms and conditions of the Creative Commons Attribution license (http://creativecommons.org/licenses/by/3.0/). 